\title{
Phytoplankton growth rate and nitrogen content: implications for feeding and fecundity in a herbivorous copepod
}

\author{
Thomas Kiørboe
}

Danish Institute for Fisheries and Marine Research, Charlottenlund Castle, DK-2920 Charlottenlund, Denmark

\begin{abstract}
Observations of natural feeding and egg-production rates of planktonic copepods have revealed distinct responses, independent of phytoplankton biomass, to oceanographic processes that fertilize the photic layer. Are such responses caused by changes in phytoplankton growth rate, influencing feeding behaviour, and/or by changes in the chemical composition of the phytoplankton, influencing fecundity? The diatom Thalassiosira weissflogui, grown in continuous cultures at different dilution rates and different nitrogen concentrations in the growth medium, was offered to the copepod Acartia tonsa at a concentration of $1.5 \mathrm{ppm}$. Over more than 2 orders of magnitude increase in algal growth rate, the ingested cell volume increased by less than a factor of 2 , ingested carbon remained constant whereas ingested nitrogen as well as rate of egg production increased by a factor of ca 6 . Variation in ingested cell volume was interpreted as a behavioural feeding response to variations in algal growth conditions; variation in ingested nitrogen and egg production, as being caused mainly by variation in algal nitrogen content. It is concluded that variable fecundity may potentially be explained by variable chemical composition of the algae, while the observed feeding response is probably insufficient to account for the variability observed in the sea.
\end{abstract}

\section{INTRODUCTION}

While it has long been recognized that the distribution and activity of phytoplankton in the sea depend to a large extent on oceanographic processes that fertilize the photic layer (e.g. upwellings, fronts, storm-generated vertical mixing; see Legendre 1981), a subsequent response at the herbivore trophic level to such mesoscale phenomena has only recently been demonstrated. In some such cases, a herbivore response can be readily understood in terms of variations in phytoplankton biomass and without invoking a complex behavioural feeding response. For example, Kiørboe \& Johansen (1986), Cowles et al. (1987) and Peterson \& Bellantoni (1987) found the activity (feeding, fecundity and/or population growth rate) of copepods to increase concurrent with phytoplankton biomass in response to an upwelling event, a storm event or at a tidal front. In other cases, however, the response in copepod activity to oceanographic processes, even though distinct, cannot be related to variations in phytoplankton biomass. For example, Hanson et al. (1986) observed massspecific clearance of herbivorous zooplankton to vary by 1 order of magnitude in response to an upwelling event, but to be out of phase with phytoplankton biomass variations (chlorophyll). Likewise, Kiørboe et al. (1988a, b) found the fecundity of the copepod Acartia tonsa to quadruple in response to a storm event, even though phytoplankton biomass (chlorophyll) remained constant. If this increase in fecundity was caused by increased primary production (not measured) the implication is that specific feeding rates of the zooplankton had increased, e.g. in response to enhanced growth rate or chemical composition of the phytoplankters. A similar explanation was given by Roman et al. (1986) for the observation that the vertical distribution of zooplankton grazing activity (both absolute and massspecific rates) was better correlated to phytoplankton growth rate than to phytoplankton biomass (chlorophyll).

It has been suggested that herbivorous copepods perceive algal cells by chemosensory means (Poulet \& Marsot 1978), and that elevated phytoplankton growth rate results in a larger phagostimulating envelope or 'microzone' of amino acids or other secreted molecules around individual algal cells (Cowles et al. 1988). Thus, copepods are known to select between food particles of different 'quality' in laboratory experiments 
(Donaghay \& Small 1979) and between algae of the same species but with different growth rates (Acartia tonsa; Cowles et al. 1988). However, whether copepods increase their feeding rate in response to enhanced growth conditions or chemical composition of the algae, as implicated in the above hypothesis, is less clear. Several early workers have reported that zooplankters (cladocerans, copepods) clear 'senescent' algae at a lower rate than exponentially growing algae (Ryther 1954, Conover 1956, Mullin 1963). More recently, Paffenhöfer \& Van Sant (1985 and references therein) compared copepod clearance rates on dead and living algae and found the latter to be removed fastest from suspension. Houde \& Roman (1987), on the other hand, found the maximum ingestion rate of $A$. tonsa to be higher when offered 'senescent' as opposed to exponentially growing algae. The opposite trend was, however, recorded at low algal concentrations by these workers. Finally, Cowles et al. (1988) observed maximum ingestion in $A$. tonsa to increase by 40 to $50 \%$ when fed fast compared to slow-growing algae.

Enhanced fecundity or growth of copepods in response to fertilization of the photic zone may be caused by increased feeding rate (cf. above) but may also be due to an increased content of a limiting nutrient in the phytoplankton. Thus, Checkley (1980) found the egg production rate in the copepod Paracalanus parvus to be negatively related to the $\mathrm{C}: \mathrm{N}$ ratio of ingested phytoplankton. Variable chemical composition of phytoplankton may, therefore, potentially give rise to variations in growth or fecundity in the sea.

In this paper the following questions are addressed: How is feeding and fecundity in Acartia tonsa affected by the growth rate and chemical composition (C:Nratio) of the phytoplankton? To what extent is a potential effect of growth rate mediated by variations in the chemical composition of the phytoplankton? The experiments described here were specifically designed to test such possible relations, without complications introduced by using different food particle types (Roman 1984, Paffenhöfer \& Van Sant 1985) or phytoplankton species (Checkley 1980).

\section{MATERIALS AND METHODS}

The phytoplankter Thalassiosira weissflogii was grown in continuous culture at constant illumination (ca $120 \mu \mathrm{E} \mathrm{m} \mathrm{m}^{-2} \mathrm{~s}^{-1}$ ). To vary algal growth rate the dilution rate was varied from $0.0066 \mathrm{~d}^{-1}$ to $0.87 \mathrm{~d}^{-1}$ between experiments. At each dilution rate the culture was allowed a minimum of 3 to $7 \mathrm{~d}$ to achieve equilibrium. Cell concentration was measured daily (Coulter Counter TAII, $100 \mu \mathrm{m}$ orifice), and the culture was considered in equilibrium when cell concentration was constant. To distinguish the effect of algal nitrogen content and growth rate on copepod feeding and fecundity, 2 series of experiments were conducted in which nitrogen $\left(\mathrm{NO}_{3}\right)$ concentration in the algal growth medium was 200 and $1200 \mu M$, respectively. The nutrient medium was otherwise similar to $\mathrm{f} / 2$ (Guillard 1975). Samples were taken daily for the determination of particulate $\mathrm{C}$ and $\mathrm{N}$ in the culture (Carbo-Erba $\mathrm{CHN}$-analyser). These data confirmed that the cultures were indeed in equilibrium and showed the expected relationship between $\mathrm{C}: \mathrm{N}$-ratio, dilution rate (= growth rate) and concentration of nitrogen in the algal growth medium (Fig. 1).

Determinations of Acartia tonsa feeding and egg production were made by methods similar to those described by Kiørboe et al. (1985). All experiments were carried out in the dark, at ca $17^{\circ} \mathrm{C}$ and $27 \%$ S, and with an initial algal concentration of $1.5 \mathrm{ppm}$, which is below the saturation concentration for Thalassiosira weissflogii (Houde \& Roman 1987, Jensen 1987). Female copepods that had matured within the previous week were obtained from our $A$. tonsa culture (Støttrup et al. 1986). Ten to 12 individuals were pipetted into each of 4 to $6600 \mathrm{ml}$ screw-cap bottles containing an initial concentration of $3.0 \mathrm{ppm} T$. weissflogii of the appropriate type and allowed to acclimate for $3 \mathrm{~d}$. During the subsequent $4 \mathrm{~d}$, the copepods were daily transferred to new bottles containing fresh algal suspension (1.5 ppm). During incubations bottles were mounted on a slowly rotating wheel $(1 \mathrm{rpm})$. The initial and final $(24 \mathrm{~h})$ algal concentration was estimated each day in the experimental as well as in 3 control bottles (without copepods), and ingestion rate $\left(\mu \mathrm{m}^{3}\right.$ ind. $\left.{ }^{-1} \mathrm{~d}^{-1}\right)$ was calculated by the equations of Frost (1972). Particle volume increased by $30 \%$ on the average in control bottles and decreased by 0 to $30 \%$ in experimental

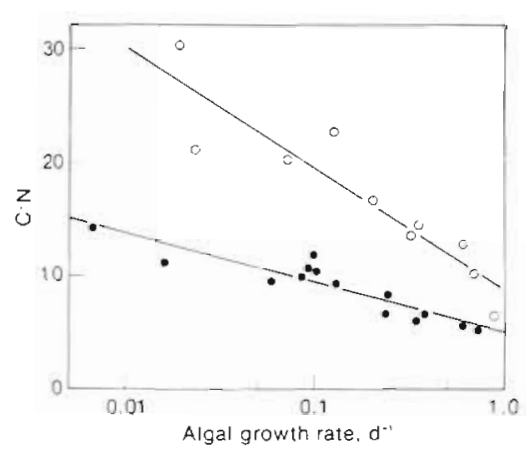

Fig. 1. Thalassiosira weissflogil. Carbon to nitrogen ratio $\left(\mathrm{C}: \mathrm{N} ; \mu \mathrm{g} \mathrm{C}_{\left.\mathrm{g} \mathrm{N} \mathrm{N}^{-1}\right)}\right.$ in diatoms grown in continuous cultures at various dilution rates $\left(\mu, \mathrm{d}^{-1}\right)$ and with different concentrations of nitrate in the growth medium. (1) $200 \mu \mathrm{MNO}_{3}, \mathrm{C}: \mathrm{N}=8.67$ $-4.68 \ln \mu_{i} r^{2}=0.84, n=10_{i}(\bullet) 1200 \mu M N_{3}, C \cdot N=4.88$ $-1.94 \ln \mu, r^{2}=0.84, n=14$ 
bottles during incubations. Spawned eggs, including empty egg membranes, were counted daily. Empty membranes constituted less than $10 \%$ of the eggs and were due to canibalism rather than hatching since no nauplii were observed. Mortality was usually low $\left(<5 \% d^{-1}\right)$. but some copepods were lost during the daily transfers when topping up and sealing the bottles, reducing the numbers remaining after $7 \mathrm{~d}$ by, on average, about $50 \%$.

At the termination of an experiment, representative individuals $(n=15)$ were measured for cephalothorax length $(\mathrm{L}, \mu \mathrm{m})$ and their body carbon $(\mathrm{W}, \mu \mathrm{g} \mathrm{C})$ estimated from $W=1.11 \times 10^{-8} \mathrm{~L}^{2.92}$ (Berggreen et al. 1988). Average weight of females used was $4.2 \mu \mathrm{g} \mathrm{C}$. Ingestion rates were generally higher on the first day following the acclimation period than during the rest of the experiment. Egg production rate had stabilized $2 \mathrm{~d}$ after the acclimation period. For data analysis, ingestion rates were integrated over the entire experiment (Days 4 to 7 ) and egg-production rates were averaged over the last $2 \mathrm{~d}$ (Days 6 and 7) Specific ingestion rates in terms of volume were converted to units of carbon and nitrogen using the $\mathrm{C}$ : volume and $\mathrm{N}$ : volume ratios measured in the algal cultures. Since the particle volume increased in the control bottles this may have caused a slight error in the estimates of $\mathrm{C}$ - and $\mathrm{N}$ ingestion. $\mathrm{C}$ and $\mathrm{N}$ content of eggs were taken to be $0.046 \mu \mathrm{g} \mathrm{C} \mathrm{egg}^{-1}$ and $0.0091 \mu \mathrm{g} \mathrm{N} \mathrm{egg}{ }^{-1}$, respectively (Kiørboe et al. 1985) and assumed to be independent of food conditions (cf. Checkley 1980).

In 4 initial experiments only ingestion rates were measured. In all other experiments, both ingestion and egg production were measured $(n=21)$. Some additional measurements were made on the algal cultures. In 2 experiments the size of Thalassiosira weissflogii cells deviated significantly from average cells size $(\bar{X}=13.4$ $\mu \mathrm{m}$ equivalent spherical diameter). An attempt to correct for the effect of cell size on ingestion and egg production rates by multiple regression resulted in unrealistically steep slopes, and it was therefore decided to omit these 2 observations from the data presentation.

\section{RESULTS}

The volume of particles ingested increased slightly but significantly with algal growth rate (Fig. 2a), but was independent of algal C:N-ratio $(r=-0.41,10 \%$ $>p>5 \%)$. Since algal concentration was similar in all experiments clearance rate varied in parallel to ingestion rate. There was a negative relationship between the carbon-to-volume ratio and the growth rate of the algae $(r=-0.87, p<0.01 \%, n=24)$, and ingested carbon remained constant and independent of growth rate (Fig. 2b) and C:N-ratio (Fig. 3a) of the algae.

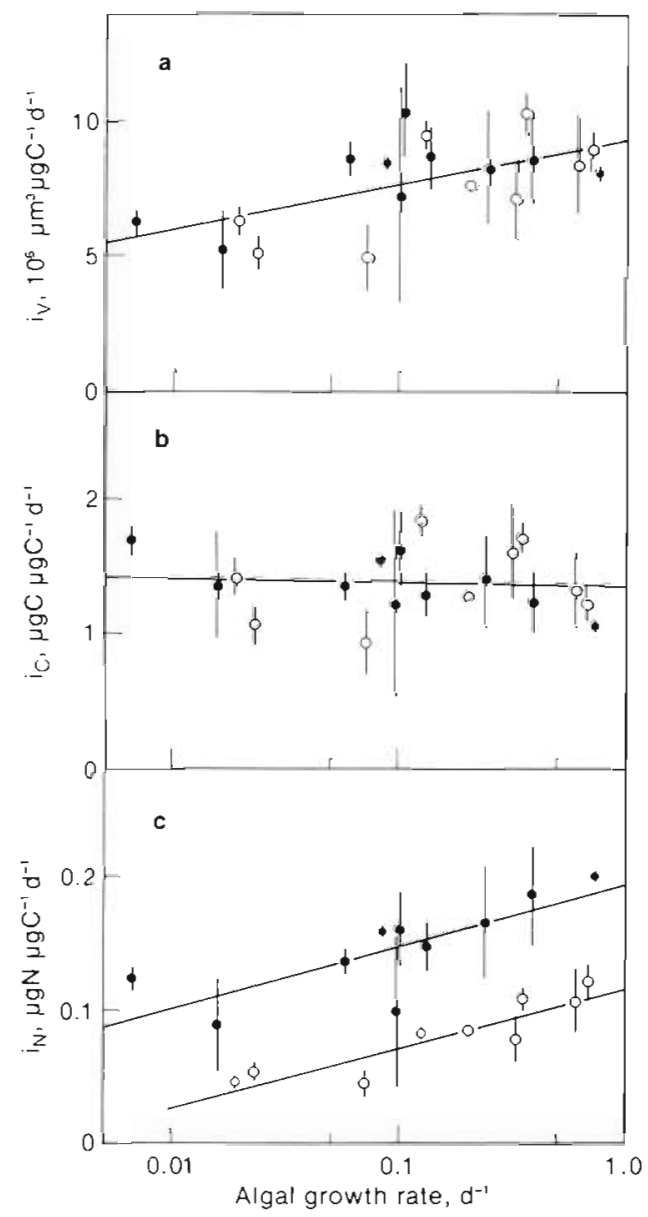

Fig. 2. Acartia tonsa females. Ingestion rate in units of (a) particle volume $\left(i_{V i} 10^{6} \mu \mathrm{m}^{3} \mu g \mathrm{C}^{-1} \mathrm{~d}^{-1}\right)$; (b) carbon $\left(\mathrm{i}_{\mathrm{C}} \mu \mathrm{g} \mathrm{C}\right.$ $\left.\mu g C^{-1} d^{-1}\right)_{i}(c)$ nitrogen $\left(i_{N} ; \mu g N \mu g C^{-1} d^{-1}\right.$ ) as a function of algal growth rate $\left(\mu, \mathrm{d}^{-1}\right)$. All measurements carried out at an algal concentration of $1.5 \mathrm{ppm}$. Bars: $\pm 1 \mathrm{SE}_{i}$ (0) $2004 M \mathrm{NO}_{3}$; (•) $1200 \mu \mathrm{MNO}_{3}$. Regressions are (a) $\mathrm{i}_{V}=9.42+0.73 \ln \mu$ $\left(r^{2}=0.36, p<1 \%\right) ;(b) i_{C}=1.34-0.02 \ln \mu\left(r^{2}=0.008\right.$, $p>10 \%) ;$ (c) $200 \mu M: i_{N}=0.116+0.019 \ln \mu\left(r^{2}=0.81\right.$, $p<0.1 \%), 1200 \mu M: \mathrm{i}_{N}=0.195+0.020 \ln \mu\left(r^{2}=0.62\right.$, $p<1 \%)$

Ingestion rate in terms of nitrogen, on the other hand, increased with algal growth rate and was significantly higher for nitrogen replete than nitrogen depleted cells (Fig. 2c). Plotting nitrogen ingestion as a function of algal C:N-ratio (Fig. 3b) or particulate nitrogen concentration (Fig. 4a), however, removes the discrepancy between nitrogen replete and depleted cells and the data can be fitted into common relationships. Therefore, variations in nitrogen ingestion were mainly due to variable nitrogen content of the food algae and independent of variations in algal growth rate per se.

The rate of Acartia tonsa egg production revealed a similar response to variations in algal growth rate (not shown), C:N-ratio (Fig. 3C, d) and particulate nitrogen (Fig. 4b) as did nitrogen ingestion, and there was a linear relationship between egg production and 


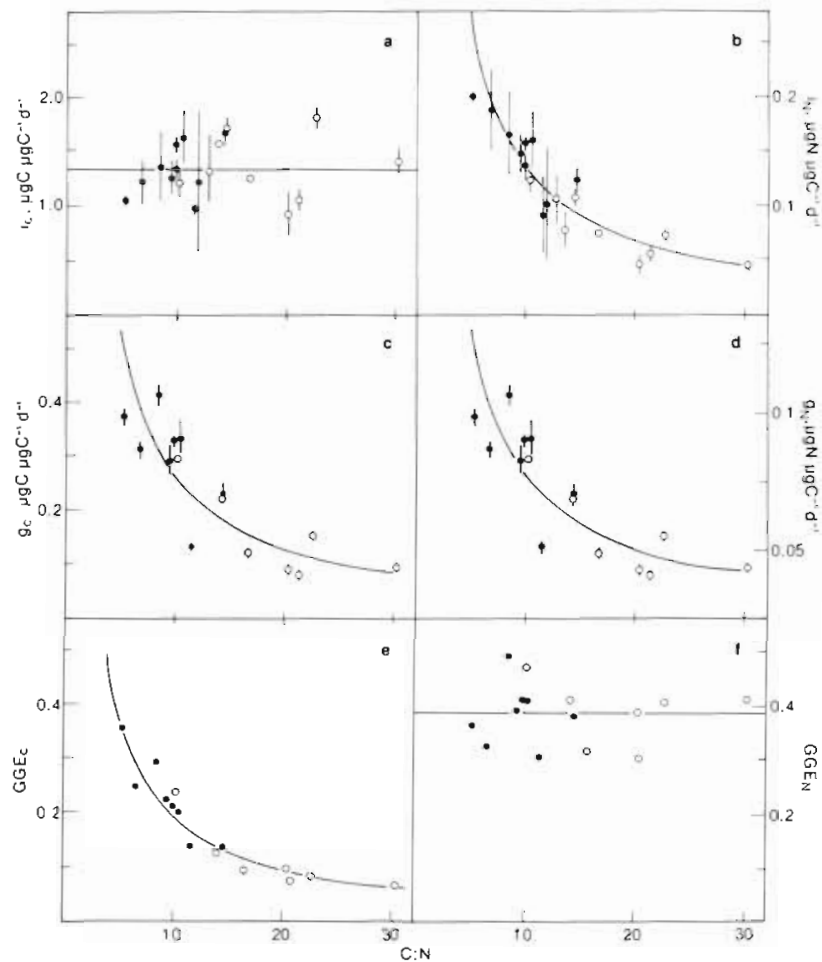

Fig. 3. Acartia tonsa females. Ingestion rate (i), egg production rate $(\mathrm{g})$ or gross egg production efficiency (GGE) in units of either carbon or nitrogen as a function of algal $\mathrm{C}: \mathrm{N}$-ratio. All measurements at an algal concentration of $1.5 \mathrm{ppm}$. Lines are (a) average $i_{C}=1.35 ;$ (b) $i_{N}=1.35 / C: N_{i}$ (c) $g_{C}=2.65 / C: N$; (d) $g_{N}=0.52 / C: N_{i}\left(\right.$ e) $G G E_{C}=1.94 / C: N_{i}$ (f) average $G G E_{N}$ $=0.38$. Symbols as for Fig. 2

ingested nitrogen $\left(g_{N}=0.364 \mathrm{i}_{\mathrm{N}}-0.002 ; r^{2}=0.87\right.$; not shown). Consequently, the gross egg production efficiency in nitrogen units $\left(G_{G E}=g_{N} / i_{N}\right)$ was independent of both growth rate and C:N-ratio of the algae (Fig. 3f) and averaged $0.384 \pm 0.057$ (SD). In contrast, $G_{C E}\left(=g_{C} / i_{C}\right)$ declined hyperbolically with increasing $\mathrm{C}: \mathrm{N}$-ratio (Fig. 3e). Only at an algal C:N-ratio that was equal to that of the eggs $(=5.05$ ) were the 2 efficiencies equal.

\section{DISCUSSION}

The present data lend little support to the idea that the often dramatic changes in copepod feeding rates observed in response to nutrient enrichment of the photic layer are caused solely by a behavioural reaction to variations in growth conditions or chemical composition of the phytoplankton. Clearance or ingested particle volume in Acartia tonsa varied by less than a factor of 2 and ingested carbon remained constant over more than a 2-order-of-magnitude variation in algal growth rate and a factor of 6 variation in $\mathrm{C}: \mathrm{N}$-ratio. The slight response in ingested particle volume is similar in mag- nitude to that observed by Houde \& Roman (1987) and Cowles et al. (1988) in the same species. As discussed by these authors, this behavioural response may be caused by increased excretion of phagostimulating substances in fast growing cells. However, the response is fairly weak, and apparently independent of the nitrogen content of the cells ( $\mathrm{cf}$. the independence of ingested volume on $\mathrm{C}: \mathrm{N}$-ratio). The much larger variation in ingested nitrogen was mainly caused by variable nitrogen content of the algae rather than a variable feeding or filtering rate. It may be, of course, that $A$. tonsa is not representative for all zooplankters in the above studies. However, the present results are not inconsistent with previous laboratory reports of copepod feeding behaviour. In my experiments, algae were not dead or 'senescent' but actively growing, albeit some of them at very low rates. Furthermore, the present experiments were specifically designed to test the effect of algal growth conditions and not the effect of various food particle types of different nutritional quality (different algal species, detritus, fecal pellets, etc.; Roman 1984, Paffenhöfer \& Van Sant 1985) on. grazing rates

In contrast, egg production followed closely variations in nitrogen content of ingested algae. Egg production efficiency in terms of nitrogen $\left(\mathrm{GGE}_{\mathrm{N}}\right)$ was constant and similar to that reported earlier for Acartia tonsa (Kiørboe et al. 1985: 0.36 to 0.41; Berggreen et al.

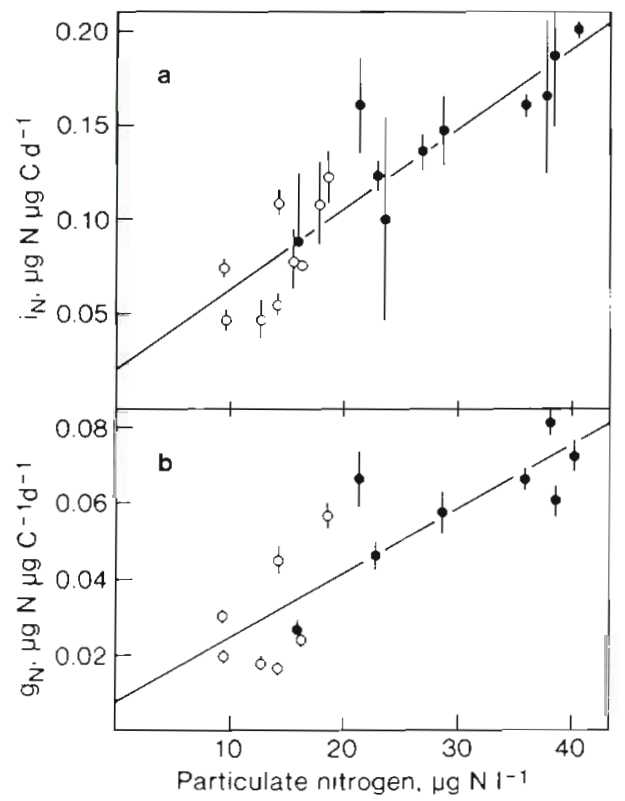

Fig. 4. Acartia tonsa females. Ingestion rate $\left(I_{N}, \mu g N \mu g C^{-1}\right.$ $\left.\mathrm{d}^{-1}\right)$ and egg production rate $\left(g_{N}, \mu g N u g C^{-1} d^{-1}\right)$ as a function of particulate nitrogen concentration $\left(P N, \mu g N^{-2}\right)$. All experiments conducted at an algal concentration of $1.5 \mathrm{ppm}$. Bars: \pm $1 \mathrm{SE}_{i}(0) 200 \mu M \mathrm{NO}_{3}(\bullet) 1200 \mu M \mathrm{NO}_{3}$. Regressions are (a) $i_{N}$ $=0.0200+0.0043 \mathrm{PN}\left(r^{2}=0.82\right):(b) \mathrm{gN}_{\mathrm{N}}=00077+0.0017 \mathrm{PN}$ $\left(r^{2}=0.72\right)$ 
1988, preadult growth efficiency: 0.44). In accordance with the present results, Checkley (1980) found $\mathrm{GGE}_{\mathrm{N}}$ to be independent of algal $\mathrm{C}: \mathrm{N}$-ratio in Paracalanus parvus (GGEN $=0.37$ to 0.44 ), $\mathrm{GGE}_{\mathrm{C}}$ to decline with increasing $C: N$-ratio and, hence, egg production to trace algal $C: N$. Such relationships suggest that nitrogen (protein) is the limiting constituent of the food and may, therefore, potentially explain field observations of enhanced fecundity of copepods in response to nutrient enrichment of the photic layer, even in cases where phytoplankton concentration remains constant.

Even though nitrogen content and C:N-ratio of phytoplankters follow the nitrogen concentration of the growth medium in laboratory experiments in Thalassiosira weissflogii (Fig. 1) and other species (Goldman 1980), it is questionable to what extent these parameters vary in natural situations. Goldman (1987) compiled $\mathrm{C}: \mathrm{N}$ : P-ratios of natural phytoplankton assemblages collected under a variety of field conditions and found only small deviations from the Redfield ratio. Although his analyses potentially included non-algal seston, it will tend to over- rather than underestimate $\mathrm{C}: \mathrm{N}$-ratios of the phytoplankton. Even in highly variable coastal waters, $\mathrm{C}: \mathrm{N}$-ratios of phytoplankton (Corrected for detritus) vary by less than a factor of 2.5 (Sakshaug \& Olsen 1986). Therefore, the present results at best yield only a partial explanation of field observations of increased zooplankton feeding and fecundity rates following nutrient enrichment of the water column and other mechanisms to explain this phenomenon should be looked for.

Fertilization of the photic layer is often caused by increased turbulent mixing. Rothschild \& Osborn (1988) showed in a theoretical study that small-scale turbulence generated by winds, tides, etc. will increase plankton contact rates, and, hence, zooplankton feeding rates. Alcaraz et al. (in press) provided indirect evidence that zooplankton feeding rates were indeed enhanced by turbulent mixing in laboratory microcosms but more direct experimental verification is needed. Species and size composition of the phytoplankton may also depend on processes related to vertical mixing and nutrient enrichment. Thus, largesized diatoms often characterize turbulent, nutrientrich environments while small flagellates dominate the surface water in stratified regions (Legendre 1981). Enhanced particle capture efficiency and, hence, zooplankton feeding rates may, therefore, be mediated by changes in size composition of the phytoplankton (cf. Peterson \& Bellantoni 1987). These alternative explanations should be approached experimentally or otherwise to further our understanding of temporal and spatial variations in zooplankton activity that are not directly related to variations in phytoplankton biomass in the sea.
Acknowledgements. I thank Hanne Juul for technical assistance in carrying out these experiments, and M. Roman and $K$. Richardson for critically commenting an earlier draft of this manuscript.

\section{LITERATURE CITED}

Alcaraz, M., Estrada, M., Marrase, C. (in press). Interaction between turbulence and zooplankton in laboratory microcosms. Proceedings 21st European Marine Biology Symposium, Institute of Oceanology, Polish Academy of Sciences, Gdansk, Poland

Berggreen, U., Hansen, B., Kiørboe, T (1988). Food size spectra, ingestion and growth of the copepod Acartia tonsa: implications for the determination of copepod production. Mar. Biol. 99: 341-352

Checkley, D. M., Jr. (1980). The egg production of a marine planktonic copepod in relation to its food supply: laboratory studies. Limnol. Oceanogr. 25: 430-446

Conover, R. J. (1956). Oceanography of Long Island Sound, 1952-1954. IV. Biology of Acartia clausii and A. tonsa. Bull. Bingham oceanogr, Coll. 15: 156-233

Cowles, T J., Olson, R. J., Chrisholm, S. W (1988). Food selection by copepods: discrimination between cells on basis of food quality. Mar. Biol. 100: 41-49

Cowles, T. J., Roman, M. R., Gauzens, A. L., Copley, N. J. (1987). Short-term changes in the biology of a warm-core ring: zooplankton biomass and grazing. Limnol. Oceanogr. 32: 653-664

Donaghay, P. L., Small, L. F. (1979). Food selection capabilities of the estuarine copepod Acartia clausii. Mar. Biol. 52: $137-146$

Frost, B. W. (1972). Effect of size and concentration of food particles on the feeding behaviour of the marine planktonic copepod Calanus finmarchicus. Limnol. Oceanogr. 17: $805-815$

Goldman, J. C. (1980). Physiological processes, nutrient availability, and the concept of relative growth rate in marine phytoplankton ecology. In: Falkowski, P. G. (ed.) Primary production in the sea. Plenum Press, New York, p. 179-193

Goldman, J, C. (1987). On phytoplankton growth rates and particulate $C: N: P$ ratios at low light. Limnol. Oceanogr 31: $1358-1363$

Guillard, R. L. (1975). Culture of phytoplankton for feeding marine invertebrates. In: Smith, W. L., Chanley, M. H., (eds.) Culture of marine invertebrate animals. Plenum Press, New York, p. 29-60

Hanson, R. B., Alvarez-Ossorio, M. T., Cal, R., Campos, M. J., Roman, M. R., Santiago, G., Varela, M., Yoder, J. A. (1986). Plankton response following a spring upwelling event in Ria de Arosa, Spain. Mar. Ecol. Prog. Ser. 32: 101-113

Houde, S. E., Roman, M. R. (1987). Effects of food quality on the functional ingestion response of the copepod Acartia tonsa. Mar. Ecol. Prog. Ser 40: 69-77

Jensen, J. (1987). Fødeindtagelse, ægproduktion og fedtsyresammensætning hos den marine planktoniske copepod Acartia tonsa. Thesis, University of Odense

Kiørboe, T., Johansen, K. (1986). Studies of a larval herring (Clupea harengus L.) patch in the Buchan area. IV. Zooplankton distribution and productivity in relation to hydrodynamic features. Dana 6: 37-51

Kiørboe, T., Møhlenberg, F., Hamburger, K. (1985). Bioenergetics of the planktonic copepod Acartia tonsa: relation between feeding, egg production and respiration, and composition of specific dynamic action. Mar. Ecol. Prog. Ser. 26: 85-97 
Kiørboe, T, Mohlenberg, F., Tiselius, P. (1988b). Propagation in marine planktonic copepods: production and mortality of eggs. Hydrobiologia 167/168: 219-225

Kiorboe, T., Munk, P., Richardson, K., Christensen, V. Paulsen, H. (1988a). Plankton dynamics and herring larval growth, drift and survival in a frontal area. Mar. Ecol. Prog Ser. 44: 205-219

Legendre, L. (1981). Hydrodynamic control of marine phytoplankton production: the paradox of stability. In: Nihoul, $J$ C. J. (ed.) Ecohydrodynamics. Proc. 12th Int. Liége Colloquium on ocean hydrodynamics. Elsevier, Amsterdam, p. 191-297

Mullin, M. M. (1963). Some factors affecting the feeding of marine copepods of the genus Calanus. Limnol. Oceanogr 8: $239-250$

Paffenhöfer, G.-A., Van Sant, K. B. (1985). The feeding response of a marine planktonic copepod to quantity and quality of particles. Mar. Ecol. Prog. Ser. 27: 55-65

Peterson, W. T., Bellantoni, D. C. (1987). Relationship between water-column stratification, phytoplankton cell size and copepod fecundity in Long Island Sound and off central Chile. S. Afr. J. mar. Sci. 5: 411-421

This article was submitted to the editor
Poulet, S. A., Marsot, P. (1978). Chemosensory grazing by marine calanoid copepods (Arthropoda: Crustacea). Science 200: $1403-1405$

Roman, M. R. (1984). Utilization of detritus by the copepod, Acartia tonsa. Limnol. Oceanogr 29: 949-959

Roman, M. R., Yentsch, C. S., Gauzens, A. L., Phinney, D. A. (1986). Grazer control of the fine-scale distribution of phytoplankton in warm-core Gulf Stream rings. J. mar. Res. 44: 795-813

Rothschild, B. J., Osborn, T R. (1988). Small-scale turbulence and plankton contact rates. J. Plankton Res. 10: 465-474

Ryther, J. H. (1954). Inhibitory effects of phytoplankton on the feeding of Daphnia magna with reference to growth, reproduction, and survival. Ecology 35: 522-533

Sakshaug, E., Olsen, Y (1986). Nutrient status of phytoplankton blooms in Norwegian waters and algal strategies for nutrient competition. Can. J. Fish. aquat. Sciences 43 : 389-396

Stettrup, J. G., Richardson, K., Kierkegaard, E., Pihl, N. J. (1986). The cultivation of Acartia tonsa Dana for use as live food source for marine fish larvae. Aquaculture 52: $87-96$

Manuscript first received: December 22, 1988

Revised version accepted: April 29, 1989 